Article

\title{
A Terahertz CMOS $V$-Shaped Patch Antenna with Defected Ground Structure
}

\author{
Hyeongjin Kim, Wonseok Choe and Jinho Jeong * \\ Department of Electronic Engineering, Sogang University, 35 Baekbeom-ro, Mapo-gu, Seoul 04107, Korea; \\ ilyrs486@gmail.com (H.K.); rhuphy@naver.com (W.C.) \\ * Correspondence: jjeong@sogang.ac.kr; Tel.: +82-02-705-8934
}

Received: 20 June 2018; Accepted: 25 July 2018; Published: 26 July 2018

\begin{abstract}
In this paper, a $V$-shaped patch antenna with defected ground structure is proposed at terahertz to overcome the limited performance of a standard complementary metal-oxide semiconductor (CMOS) patch antenna consisting of several metal layers and very thin interdielectric layers. The proposed $V$-shaped patch with slots allows the increased radiation resistance and broadband performance. In addition, the patch resonating at different frequency from the $V$-shaped patch is stacked on the top to broaden the impedance-matching bandwidth. More importantly, the slots are formed in the ground plane, which is called the defected ground structure, to further increase the radiation resistance and thus improve the bandwidth and efficiency. It is verified from electromagnetic simulations that the leakage waves from the defected ground can enhance the antenna directivity and gain by coherently interfering with the topside radiation. The proposed on-chip antenna is fabricated using a standard $65 \mathrm{~nm}$ CMOS process. The on-wafer measurement shows very wide bandwidth in input reflection coefficient $(<-10 \mathrm{~dB})$, greater than $28.7 \%$ from 240 to $>320 \mathrm{GHz}$. The measured peak gain was as high as $5.48 \mathrm{dBi}$ at $295 \mathrm{GHz}$. To the best of the authors' knowledge, these results belong to the best performance among the terahertz CMOS on-chip antennas without using additional components or processes such as dielectric resonators, lens, or substrate thinning.
\end{abstract}

Keywords: antenna; CMOS; defected ground structure; patch; terahertz

\section{Introduction}

Recently, there has been active research on terahertz (THz) communication, sensing, and imaging systems using semi-conductor transistor technologies such as silicon (Si) complementary metal-oxide semiconductor (CMOS) field effect transistors (FETs), gallium arsenide (GaAs) or indium phosphide $(\mathrm{InP})$ heterojunction bipolar transistors (HBTs), and high-electron mobility transistors (HEMTs) [1-4]. The $\mathrm{THz}$ monolithic integrated circuits (TMICs) that use these technologies allow for lower cost, higher integration, and miniaturization of THz systems, compared with optics-based components [5-10].

$\mathrm{THz}$ antennas with high radiation efficiency and broad bandwidth are indispensable in the front-end stage of TMICs for communication, sensing, and imaging systems. Basically, off-chip antennas can provide broadband and high efficiency performance by using low-loss substrates such as low-temperature co-fired ceramic (LTCC) and artificial dielectrics [11,12]. However, parasitic components such as bonding wires and interconnection lines used in the connection of TMICs and off-chip antenna can result in the severe performance degradation (impedance mismatch and insertion loss), poor repeatability, and increased cost.

On the contrary, on-chip antennas can effectively avoid these drawbacks by eliminating off-chip bonding wires and interconnection lines [13]. Especially, the antenna size can be drastically reduced due to the very short wavelengths at $\mathrm{THz}$ frequencies, so that the antenna can be integrated onto $\mathrm{Si}$ CMOS ICs. Therefore, the on-chip antenna approach allows low-cost and repeatable $\mathrm{THz}$ solutions 
for mass production. Generally, CMOS on-chip antennas with front-side radiation are designed using several metal and interlayer dielectric layers, where the bottom metal layer is used as a ground plane to shield the high-conductivity Si substrate and minimize dielectric loss [14,15]. In this case, the metallic ground plane in proximity to the top patch creates an image problem and cancels out the radiated field by the patch. A metamaterial or reactive impedance surface (RIS) technique can be used to replace the metallic ground plane in order to mitigate this problem and enhance the bandwidth and efficiency [16-18]. Anyway, a very thin dielectric between the radiating element and ground in CMOS on-chip antenna results in low radiation resistance and thus narrow bandwidth and poor efficiency, both around $10 \%[13,19]$ at the $\mathrm{THz}$ frequency.

Several approaches have been introduced to improve the bandwidth and efficiency of the CMOS on-chip antenna. In [20], a dielectric resonator was stacked on the on-chip patch antenna providing an excellent efficiency of $80 \%$ with a bandwidth of $11 \%$ at $344 \mathrm{GHz}$ in a $130 \mathrm{~nm}$ CMOS process. However, this 3-dimensional antenna requires an additional process to adhere the etched dielectric onto the fabricated antenna using an epoxy glue in a high precision.

Back-side radiating antennas through the Si substrate were also proposed, showing high gain and wideband performance $[1,21]$. In this case, the electromagnetic (EM) wave can be absorbed by a high-conductivity and high-dielectric constant Si substrate in a substrate mode. In order to reduce the loss due to the substrate mode, the substrate is thinned to less than $100 \mu \mathrm{m}$ [22]. In addition, a hemispherical high-resistivity $\mathrm{Si}$ lens is attached to the backside of the substrate to increase the gain [23]. Several back-side radiating CMOS on-chip antennas have been proposed at a $\mathrm{THz}$ frequency. In $[24,25]$, a broadband bowtie antenna array was used for a THz imager in low-cost CMOS technology, where there was no ground plane, and the bowtie antenna was made up of all the metal layers. The high-resistivity Si substrate was ground down to $130 \mu \mathrm{m}$ in order to reduce the substrate loss. In [26], artificial magnetic conductors (AMCs) were adopted in the BiCMOS bowtie antenna to stop the wave from radiating through the lossy Si substrate, where AMCs function as a high impedance surface. It was shown from the simulation that the bowtie antenna can achieve about $1 \mathrm{~dB}$ higher gain $(\sim-1.9 \mathrm{~dB})$ by adopting an AMC structure at $94 \mathrm{GHz}$. However, substrate thinning and the use of a lens can decrease the reliability and increase the packaging cost.

In this paper, we propose a $V$-shaped patch antenna using a defected ground structure (DGS) operating at $\mathrm{H}$-band (220-320 GHz), to enhance the efficiency and bandwidth of a standard CMOS patch antenna. In addition, the influence of the probe tip used in on-wafer antenna measurement is analyzed through an EM simulation. Section 2 discusses the efficiency and bandwidth limitations of a standard CMOS on-chip patch antenna. The $V$-shaped patch antenna with DGS is proposed and designed in the same section, including the EM analysis of the probe effect on the antenna performance. The measurement results are presented in Section 3. Finally, Section 4 presents the conclusion.

\section{CMOS On-Chip Patch Antenna Design}

\subsection{Standard CMOS On-Chip Patch Antenna}

Microstrip patch antennas are widely used as $\mathrm{THz}$ Si CMOS on-chip antennas because of their simple structure, front-side radiation, and easy integration with other transceiver circuits. In the CMOS patch antenna, the high conductivity $(\sigma=10 \mathrm{~S} / \mathrm{m})$ and high dielectric constant $\left(\varepsilon_{r}=11.9\right)$ of the $\mathrm{Si}$ substrate is generally shielded by using the bottom metal layer as a ground plane. Therefore, one of upper metal layers is selected as a radiating patch and thus the interlayer dielectric $\left(\mathrm{SiO}_{2}\right)$ serves as a substrate of the patch antenna. In the conventional sub- $\mu \mathrm{m}$ CMOS process, the available thickness of the $\mathrm{SiO}_{2}\left(\varepsilon_{r}=4.3\right)$ layer is less than a few tenths of a micrometer. This reduces the radiation resistance of the patch antenna, which leads to severe degradation in radiation efficiency and bandwidth.

In order to investigate the effect of the substrate thickness, a standard CMOS patch antenna was designed at $300 \mathrm{GHz}$, as shown in Figure 1. It consisted of very thin $\mathrm{SiO}_{2}$ dielectric layer as a substrate. Figure 2 shows the simulation results of a designed patch antenna by using a commercial 
full-wave simulator (Ansoft High Frequency Structure Simulator (HFSS)). If metal layers were set to a perfect electric conductor (PEC), the standard patch maintained a very high radiation efficiency of around $96.1 \%$ when the substrate thickness varied from 1 to $12 \mu \mathrm{m}$, as shown in Figure 2a. In this simulation, the loss tangent of the substrate was assumed to be 0.001 for simulation purposes [27]. However, the efficiency rapidly dropped for copper $(\mathrm{Cu})$ metal layers, because of its finite conductivity $\left(\sigma=5.2 \times 10^{7} \mathrm{~S} / \mathrm{m}\right)$. Furthermore, the efficiency dramatically degraded from 37.5 to $12.3 \%$ as the substrate thickness decreased from 10 to $5 \mu \mathrm{m}$. Note that the patch size was varied in the simulation to maintain the same resonance frequency depending on the substrate thickness. The radiation efficiency in the simulation was the ratio of total radiated power $\left(P_{\text {rad }}\right)$ to source-unavailable power $\left(P_{a v s}\right)$, but with input power $\left(P_{i n}\right)$, or $\eta_{i n}=P_{\text {rad }} / P_{i n}$. That is, the simulated radiation efficiency $\left(\eta_{i n}\right)$ in this paper did not take into account the antenna input mismatch (or input reflection coefficient, $\left|S_{11}\right|$ ). A more practical definition of the efficiency is $\eta_{a v s}=\frac{P_{\text {rad }}}{P_{a v s}}=\left(1-\left|S_{11}\right|^{2}\right) \eta_{i n}$. The simulated performance of the designed antenna is presented in the paper using radiation efficiency $\left(\eta_{i n}\right)$ and input reflection coefficient $\left(\left|S_{11}\right|\right)$.

Figure $2 \mathrm{~b}$ shows that the standard CMOS patch exhibited a very narrow input reflection coefficient $\left(20 \log \left|S_{11}\right|\right)$ due to a very thin substrate thickness of $4.49 \mu \mathrm{m}$. That is, the fractional bandwidth of the input reflection coefficient $<-10 \mathrm{~dB}$ was just 0.3 and $3.0 \%$ for the PEC and $\mathrm{Cu}$ patch, respectively.

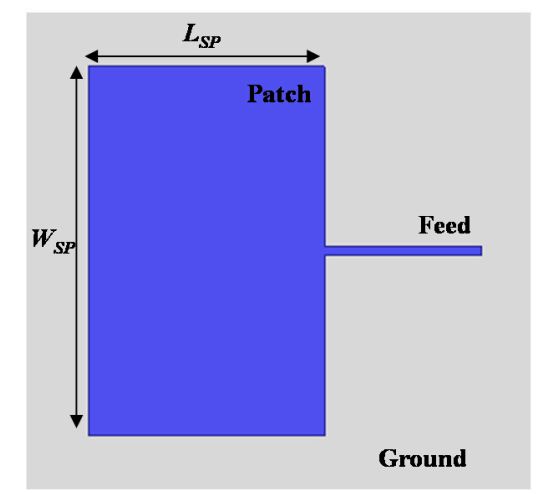

Figure 1. Top view of THz on-chip patch antenna.

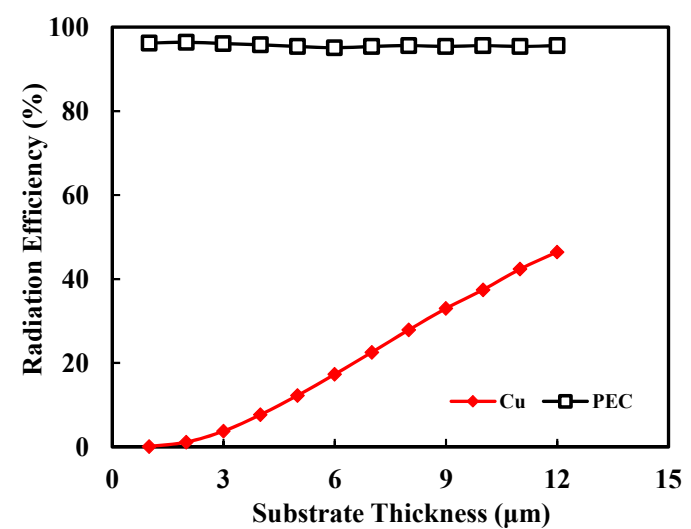

(a)

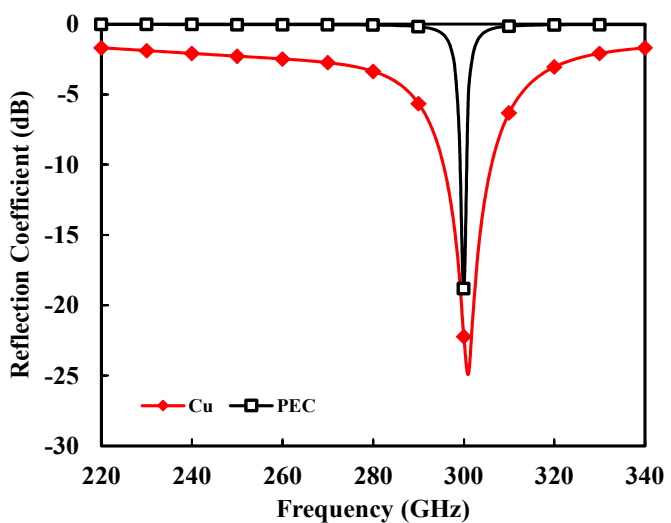

(b)

Figure 2. Simulation of the standard CMOS patch antenna. (a) Radiation efficiency according to substrate thickness (at a fixed frequency of $300 \mathrm{GHz}$ ). (b) Reflection coefficient $\left(\left|S_{11}\right|\right)$ with frequency $\left(W_{S P}=345 \mu \mathrm{m}, L_{S P}=225 \mu \mathrm{m}\right.$, and substrate thickness of $\left.4.49 \mu \mathrm{m}\right)$.

In summary, the standard CMOS patch antenna exhibited very low efficiency and narrowband performance, which were caused by low radiation resistance and high conductor loss mainly due 
to a very thin substrate. In this work, we proposed a V-shaped patch antenna with DGS to improve the efficiency and bandwidth of the CMOS patch antenna. Figure 3 shows the metal/dielectric layer structure in a commercial $65 \mathrm{~nm}$ CMOS process used for the on-chip antenna design in this work. It consisted of a total of 10 metal layers with dielectric $\left(\mathrm{SiO}_{2}\right)$ interlayers. The top metal layer, M10 in aluminum ( $\mathrm{Al})$, is generally used as bias lines in IC. Note that M9 $(\mathrm{Cu})$ had a higher conductivity and higher thickness than M10 (Al). In the patch antenna design, therefore, the M9 layer is selected instead of M10 as a radiating patch, in order to reduce the conductor loss. The other metal layers (M1-M8) in $\mathrm{Cu}$ were very thin $(0.1-0.3 \mu \mathrm{m})$, resulting in high conductor loss.

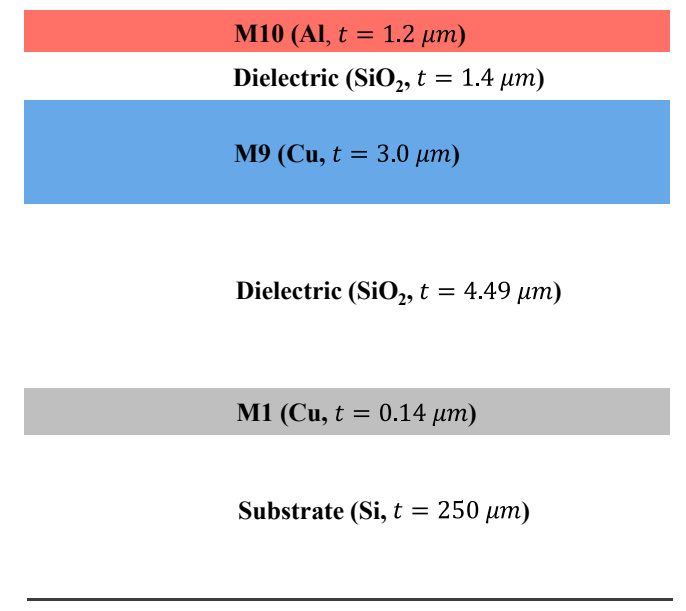

Figure 3. Cross-sectional view of the $65 \mathrm{~nm}$ Si CMOS process.

\subsection{V-Shaped Patch Antenna}

Figure 4 a shows the proposed $V$-shaped patch with M9 and M1 layers as the patch and ground, respectively. The $V$-shaped patch can increase the radiation resistance compared with the rectangular patch, while the slots formed in the patch improving the matching bandwidth [28,29]. The $V$-shaped patch was designed to have a resonant frequency of around $300 \mathrm{GHz}$. In addition, a rectangular resonator (M10) was stacked on the patch. Its size was determined to provide a resonant frequency (around $325 \mathrm{GHz}$ ) that was different from the M9 $V$-shaped patch (around $300 \mathrm{GHz}$ ), to broaden the matching bandwidth. The proposed patch antenna exhibited a bandwidth of $15.5 \%$, which was $12.5 \%$ higher than the standard patch antenna, as shown in Figure $4 \mathrm{~b}$. The bandwidth in this paper was defined as the frequency band meeting the input reflection coefficient $\left(20 \log \left|S_{11}\right|\right)$ of lower than $-10 \mathrm{~dB}$. The simulated directivity was $7.6 \mathrm{dBi}$ and the gain was $-0.4 \mathrm{dBi}$, at $300 \mathrm{GHz}$.

In the above simulation, $\mathrm{M} 1$ was only used as a ground plane to obtain the highest $\mathrm{SiO}_{2}$ substrate. However, M1 was very thin $(0.14 \mu \mathrm{m}$-thick) so that the conductor loss in the ground plane could be very large. If more metal layers are used as a ground plane, the conductor loss can be reduced. Figure $4 \mathrm{c}$ shows the simulated radiation efficiency of the $V$-shaped patch antenna according to the metal layer composition of the ground plane. The ground plane, consisting of M1 and M2, allowed for the best efficiency performance, or a $4 \%$ increase at $300 \mathrm{GHz}$ compared with the M1-only ground. On the other hand, when all M1, M2, and M3 layers were used as a ground, and the conductor loss increased due to the decrease of the dielectric thickness. Therefore, the M1-M2 ground plane was used in the patch antenna. 


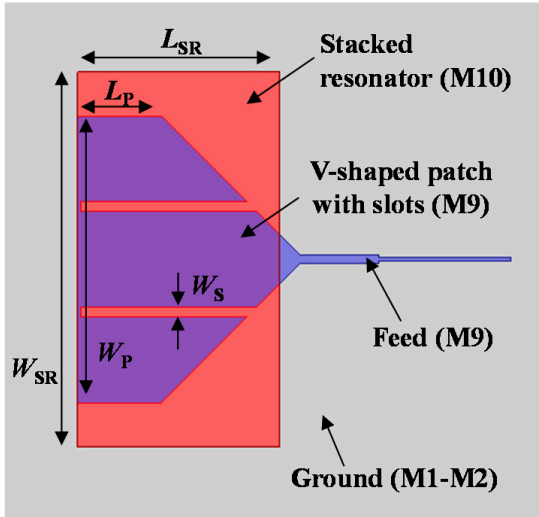

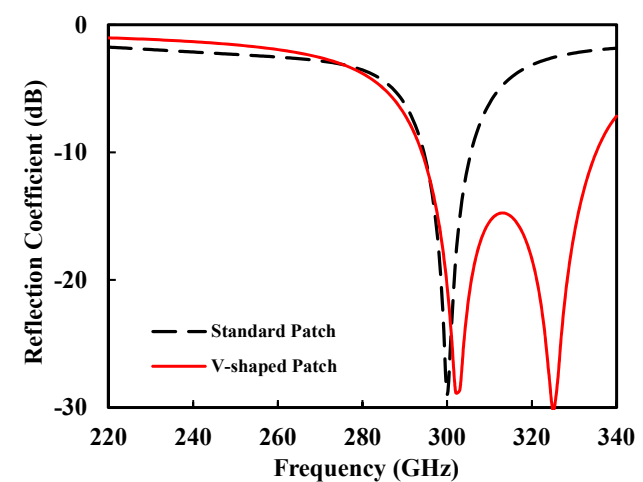

(b)

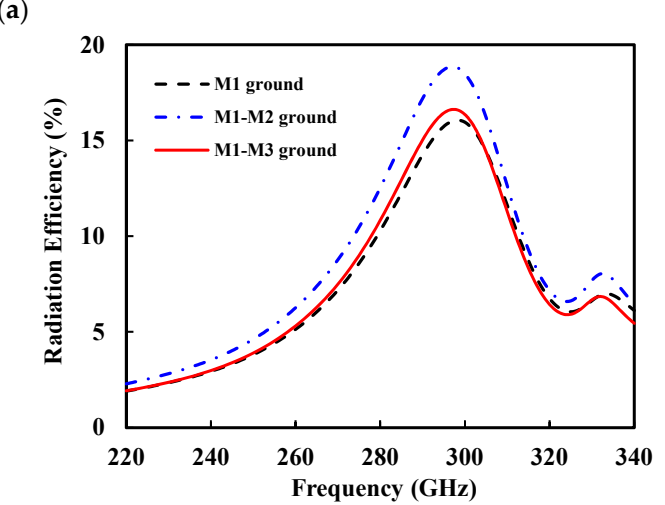

(c)

Figure 4. (a) Top view of the proposed $V$-shaped patch antenna $\left(W_{P}=325 \mu \mathrm{m}, L_{P}=95 \mu \mathrm{m}, W_{S}=10 \mu \mathrm{m}\right.$, $W_{S R}=425 \mu \mathrm{m}, L_{S R}=230 \mu \mathrm{m}$, feed width/length $=9 \mu \mathrm{m} / 90 \mu \mathrm{m}, 50 \Omega$-line width $=4 \mu \mathrm{m}$ ). (b) Simulated reflection coefficient $\left(\left|S_{11}\right|\right.$ ). (c) Simulated efficiency according to the metal layer composition of the ground plane.

\subsection{V-Shaped Patch Antenna with a Defected Ground Structure}

As stated above, a very thin dielectric in a CMOS on-chip patch antenna reduces the radiation resistance leading to low efficiency and narrow bandwidth. In order to increase the radiation resistance, we proposed the defected ground structure (DGS), in which the repetitive slots are formed in the ground plane, as shown in Figure 5a,b. These slots reduce the capacitance between the radiating patch and the ground, resulting in an increase in radiation resistance. Figure $5 c$ compares the simulated radiation resistance of the standard patch and $V$-shaped patch without DGS, and the $V$-shaped patch with DGS, showing that $V$-shape and DGS effectively increased the radiation resistance across a wide bandwidth.

However, the DGS allows some parts of the EM wave to leak into the lossy Si substrate, which can increase the dielectric loss. Therefore, the slot size (width $W_{D G S}$, length $L_{D G S}$, and spacing $S_{D G S}$ ) was optimized for maximum efficiency through EM simulation of the structure shown in Figure 5b. Figure 6 shows the simulated efficiency and reflection coefficient of the $V$-shaped patch antenna with DGS as a function of slot width $\left(W_{D G S}\right)$, where the total width $\left(4 \times W_{D G S}+3 \times S_{D G S}\right)$ and length $L_{D G S}$ are fixed to 465 and $240 \mu \mathrm{m}$, respectively. The slot width $W_{D G S}$ of $101.25 \mu \mathrm{m}$ presents a maximum efficiency of $52 \%$ at $260 \mathrm{GHz}$ as shown in Figure 6a. However, the $-10 \mathrm{~dB}$ reflection coefficient bandwidth was not the best, and our target frequency was around $300 \mathrm{GHz}$. Thus, we selected $W_{D G S}$ of $86.25 \mu \mathrm{m}$, which allowed for a maximum efficiency of $46 \%$ at $295 \mathrm{GHz}$ and a bandwidth of $15.2 \%$. All the antenna dimensions were optimized considering bandwidth and efficiency at a center frequency of $300 \mathrm{GHz}$. Table 1 lists the optimized antenna parameters. Note that the wavelength in the air was $1 \mathrm{~mm}$ at $300 \mathrm{GHz}$. 


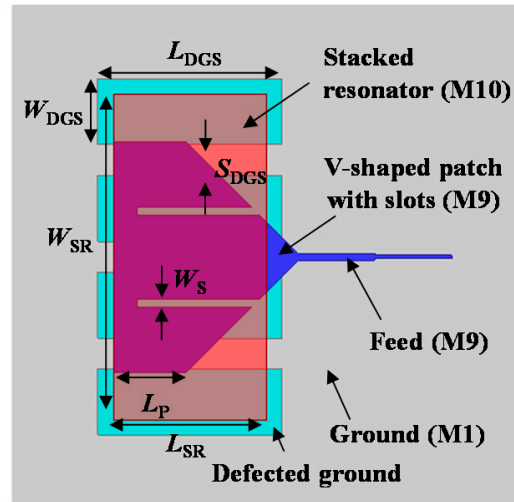

(a)

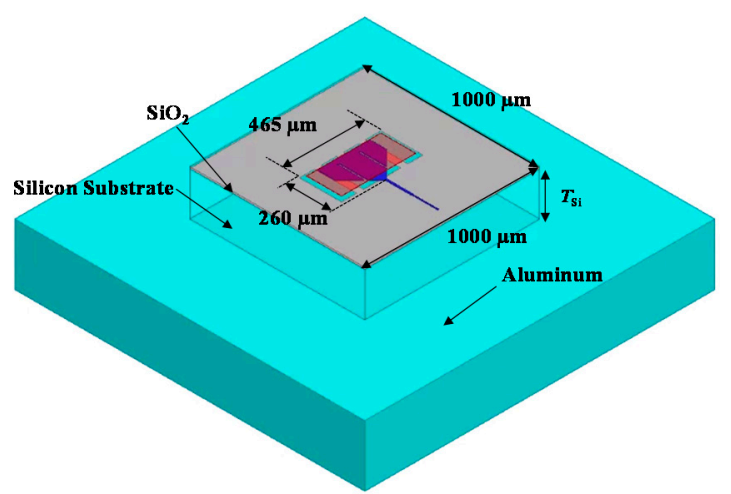

(b)

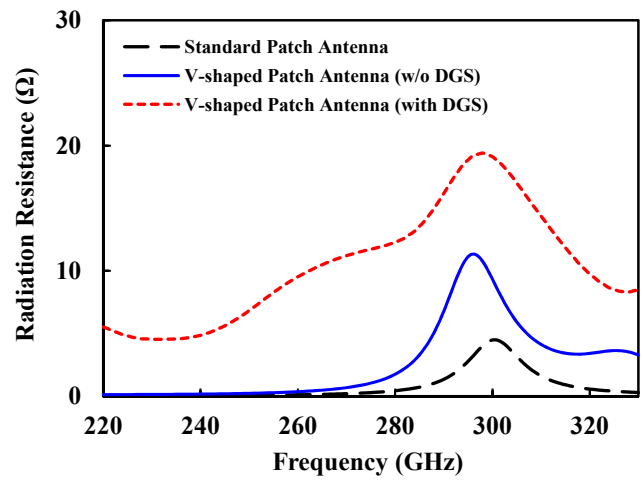

(c)

Figure 5. (a) Top view of the proposed $V$-shaped patch antenna with a defected ground structure (DGS); (b) HFSS simulation model of the proposed on-chip antenna, including the backside metal (aluminum); (c) Simulated radiation resistance of the patch antennas.

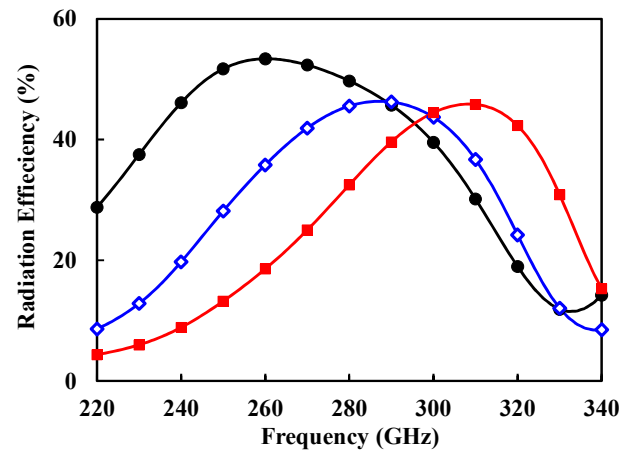

(a)

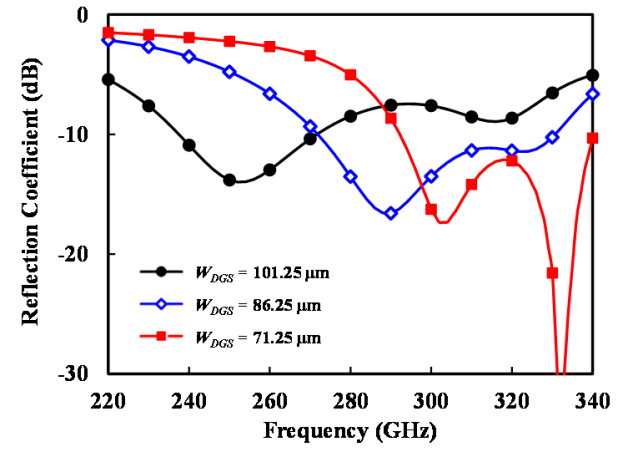

(b)

Figure 6. Simulation results of the V-shaped patch antenna with DGS depending on the slot width $\left(\mathrm{W}_{\text {DGS }}\right)$. (a) Efficiency. (b) Reflection coefficient $\left(\left|S_{11}\right|\right)$.

Table 1. Design parameters of the proposed on-chip antenna.

\begin{tabular}{ccccccccc}
\hline Parameter & $L_{S R}$ & $L_{P}$ & $W_{S R}$ & $W_{P}$ & $W_{S}$ & $L_{D G S}$ & $W_{D G S}$ & $S_{D G S}$ \\
\hline Value $(\mu \mathrm{m})$ & 200 & 95 & 425 & 300 & 5 & 240 & 86 & 40 \\
\hline
\end{tabular}

The patch antenna basically generates front-side radiation as illustrated in Figure 7a. The back-side radiation from the patch could leak into the Si substrate through the slots on the ground plane. Some part of the leakage wave was dissipated in the lossy Si substrate in the form of a surface wave. 
The remaining wave was reflected by the backside ground plane (aluminum in Figure 7a) and returned to the patch, generating interference with the front-side radiating wave. Figure $7 \mathrm{~b}$ shows the electric field distribution of the designed $V$-shaped patch antenna with DGS on the $250 \mu \mathrm{m}$-thick Si substrate at $300 \mathrm{GHz}$. There is a relatively strong leakage wave inside the Si substrate. Actually, if thickness of Si substrate $\left(T_{S i}\right)$ satisfied (1), the two waves (front-side radiating wave and the reflected wave by the backside ground) added in phase and increased both the directivity and the gain of the antenna:

$$
T_{S i}=(2 k+1) \frac{\lambda_{g}}{4},(k=0,1,2,3, \cdots)
$$

where $\lambda_{g}$ is a guided wavelength in the silicon and is about $290 \mu \mathrm{m}$ at $300 \mathrm{GHz}$.

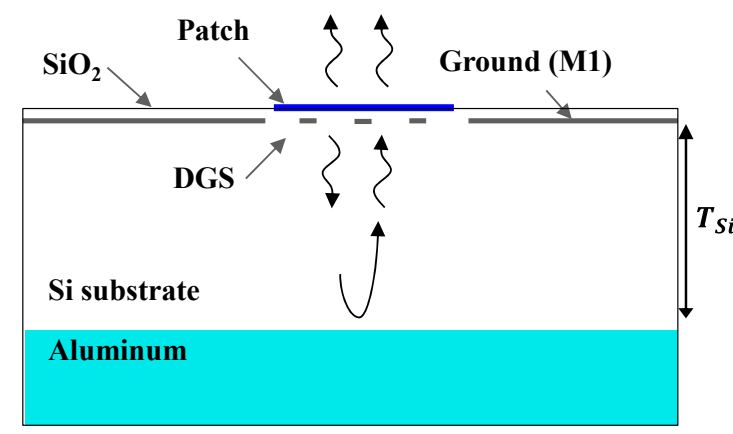

(a)

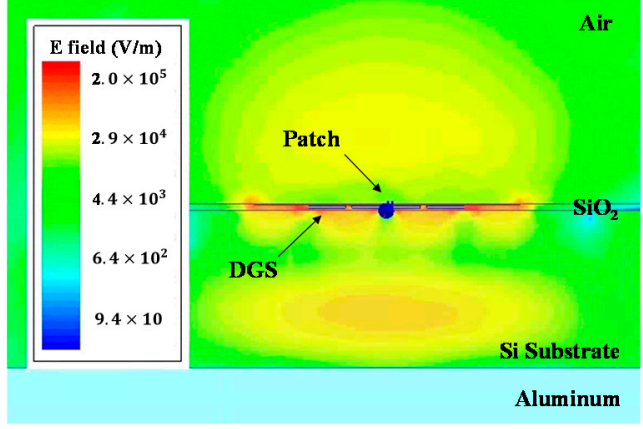

(b)

Figure 7. (a) Diagram of radiating waves in the proposed antenna. (b) E-field distribution of the proposed antenna.

Figure 8 shows the simulated gain and directivity of the V-shaped patch antenna with DGS at $300 \mathrm{GHz}$, depending on $T_{S i}$. The gain is maximized around $T_{S i}=72.5 \mu \mathrm{m}\left(\lambda_{g} / 4\right)$ and $217 \mu \mathrm{m}\left(3 \lambda_{g} / 4\right)$ and minimized around $T_{S i}=145 \mu \mathrm{m}\left(\lambda_{g} / 2\right)$ and $290 \mu \mathrm{m}\left(\lambda_{g}\right)$, respectively, as expected from (1). With a substrate thicker than $300 \mu \mathrm{m}$, the leakage wave could propagate through the Si substrate guided by the M1-M2 and backside ground planes (like parallel-plate waveguide), so that the gain rapidly decreased, as shown in Figure 8 [30]. The Si substrate used in this work had $T_{S i}=250 \mu \mathrm{m}$, which corresponded to $0.86 \lambda_{g}$ close to $3 \lambda_{g} / 4$. It led to the additive interference and an increase in directivity and gain. The designed $V$-shaped patch antenna with DGS resulted in a high directivity of $9.72 \mathrm{~dB}$ and a high gain of $3.37 \mathrm{~dB}$ at $300 \mathrm{GHz}$.

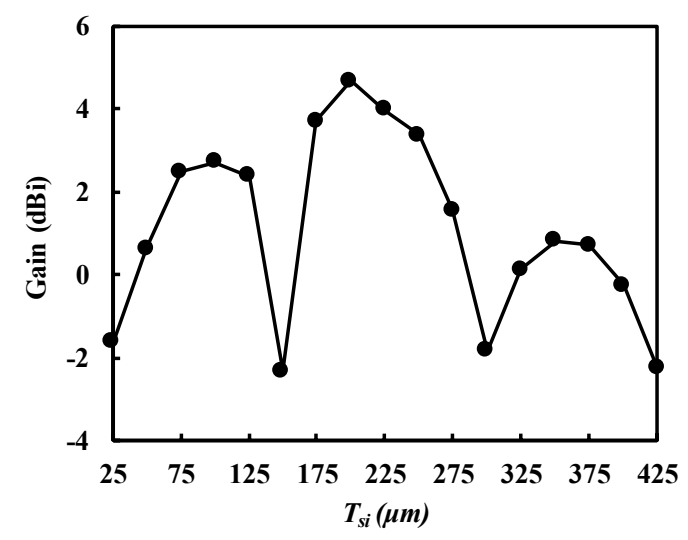

(a)

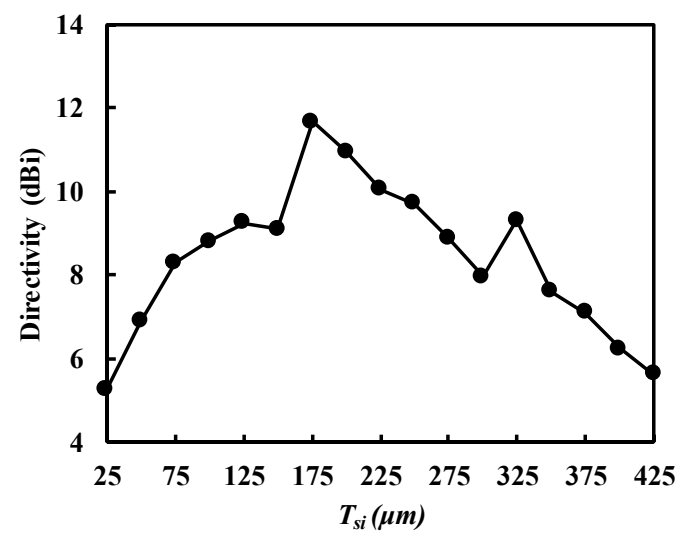

(b)

Figure 8. Simulated gain with respect to the thickness of Si substrate $\left(T_{S i}\right)$. (a) Gain. (b) Directivity. 


\subsection{Probe Effect on the Antenna Performance}

The performance of the fabricated on-chip antenna, such as input reflection coefficient, gain, and radiation pattern, was measured by on-wafer probing. The metallic probe was placed 300 $\mu \mathrm{m}\left(0.3 \lambda_{0}\right.$ at $\left.300 \mathrm{GHz}\right)$ apart from the radiating antenna, so that it could affect the radiation performance [31]. In other words, the probe tip reflects the EM wave radiated by the on-chip antenna, leading to the distortion of antenna radiation pattern [32].

In this work, we performed EM simulation of the on-chip antenna with the probe tip included, as shown in Figure 9a. For the simplicity of the simulation, the probe tip was modeled as a gold triangular prism. Figure $9 \mathrm{~b}$ shows the simulated radiation patterns (with and without probe) at $300 \mathrm{GHz}$. The simulation including the probe, exhibited a narrower beam-width in both $E$ - and $H$-planes. This result implicated that the probe used in the on-wafer measurement could create the wave reflections and result in higher directivity [33]. Figure 9c,d show that the directivity and gain could be increased by $0-0.7 \mathrm{~dB}$ at a frequency range from 270 to $300 \mathrm{GHz}$, and the radiation efficiency was rather reduced by $0-1 \%$ due to the probe. The simulation showed that the probe had a negligible effect on the input impedance match.

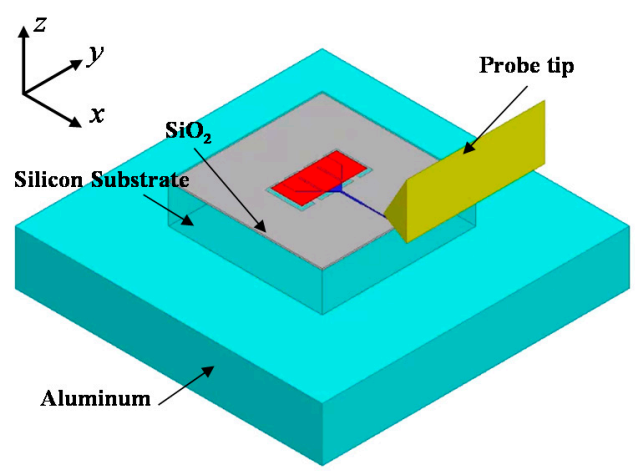

(a)

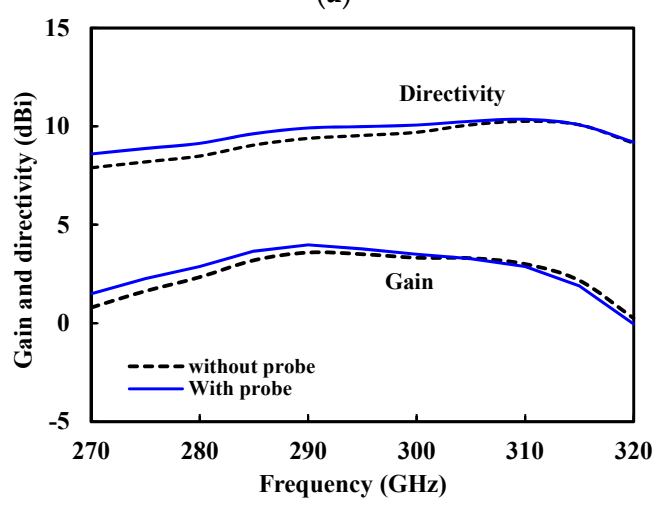

(c)

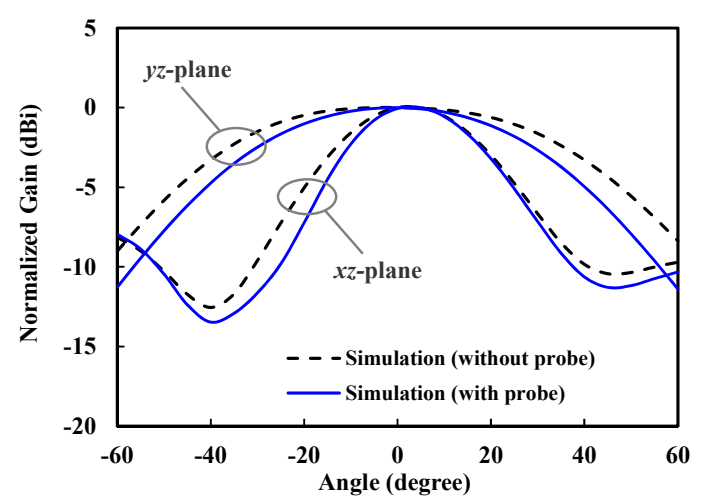

(b)

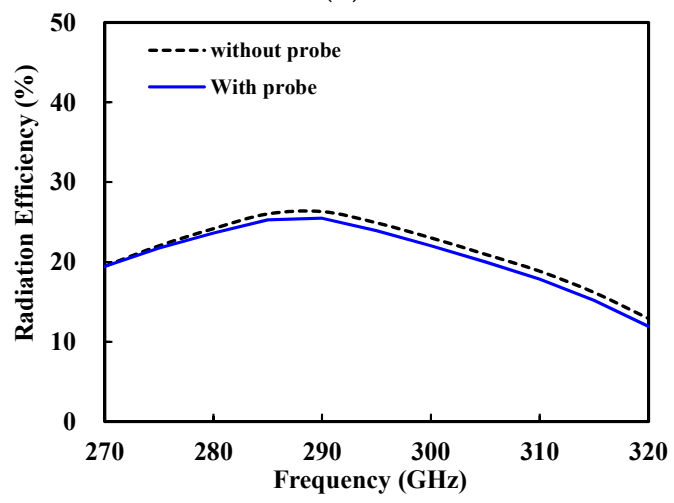

(d)

Figure 9. (a) Electromagnetic (EM) simulation of the on-chip antenna with the probe tip included. (b) Simulated radiation pattern at $300 \mathrm{GHz}$. (c) Simulated gain and directivity. (d) Simulated radiation efficiency.

\section{Measurement}

\section{Measurement of the On-Chip Antenna}

The designed $V$-shaped patch antenna with DGS was fabricated using a commercial $65 \mathrm{~nm}$ CMOS process. Figure 10a shows the photograph of the fabricated antenna. The chip size was $0.71 \mathrm{~mm} \times 0.74 \mathrm{~mm}$, including the radio frequency $(\mathrm{RF})$ probe pad. 
Figure $10 \mathrm{~b}$ shows the measured reflection coefficient of the fabricated on-chip antenna at H-band, using a vector network analyzer and WR-03 frequency extenders. It exhibited a very wide band performance, from 240 to $>320 \mathrm{GHz}$ (fractional bandwidth $>28.7 \%$ ), with a reflection coefficient better than $-10 \mathrm{~dB}$. It is also shown that the simulation agreed well with the measurement.

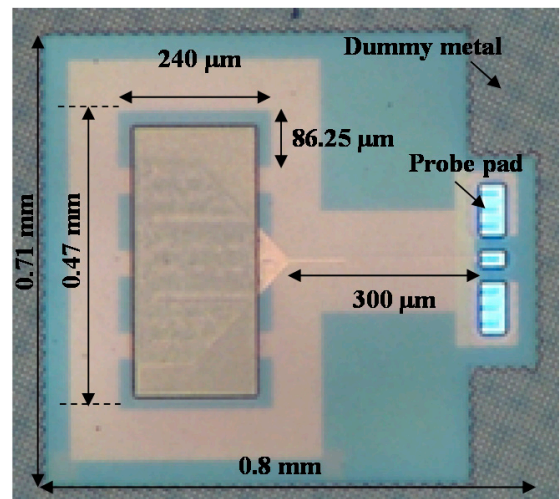

(a)

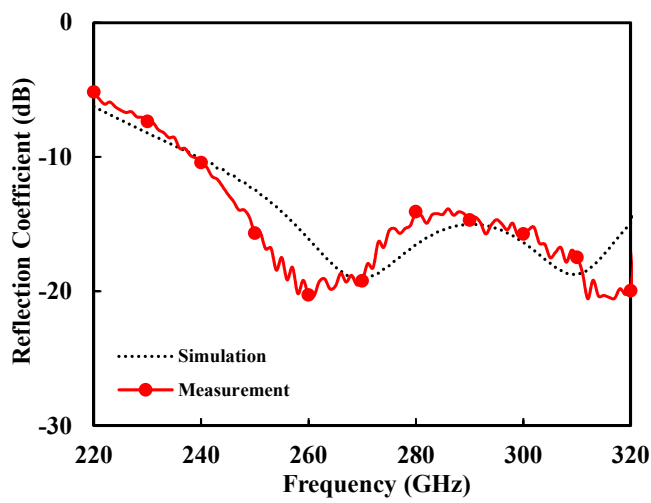

(b)

Figure 10. (a) Photograph of the fabricated on-chip antenna. (b) Measured input reflection coefficient of the proposed antenna.

The gain and radiation pattern were measured by on-wafer probing using the THz on-chip antenna measurement setup developed by the authors, as shown in Figure 11. An $H$-band signal was generated using a signal generator $(12.2-18.4 \mathrm{GHz})$ and frequency multiplier chains $(\times 18)$, and it was applied to the antenna under test (AUT) through the probe. The radiated power from the AUT was measured by the detector with a standard horn antenna that was mounted on the spherical scanner. Therefore, the radiation pattern could be measured by manually changing the angle of the detector in the $E$ - and $H$-planes.

The gain of AUT $\left(G_{A U T}\right)$ was measured based on the gain comparison method [34,35]. That is, the received power $\left(P_{r, A U T}\right)$ was measured using the setup shown in Figure 11. Then, the AUT was replaced with a standard horn antenna with a known gain $\left(G_{\text {horn }}\right)$. The received power $\left(P_{r, h o r n}\right)$ was compared with $P_{r, A U T}$ to determine $\left(G_{A U T}\right)$ as follows:

$$
G_{A U T}=P_{r, \text { AUT }}-P_{r, h o r n}+G_{\text {horn }}+L_{\text {probe }}
$$

where $L_{\text {probe }}$ is the loss of the probe.

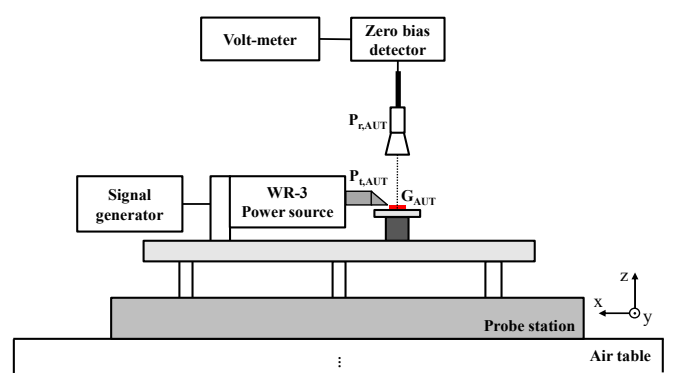

(a)

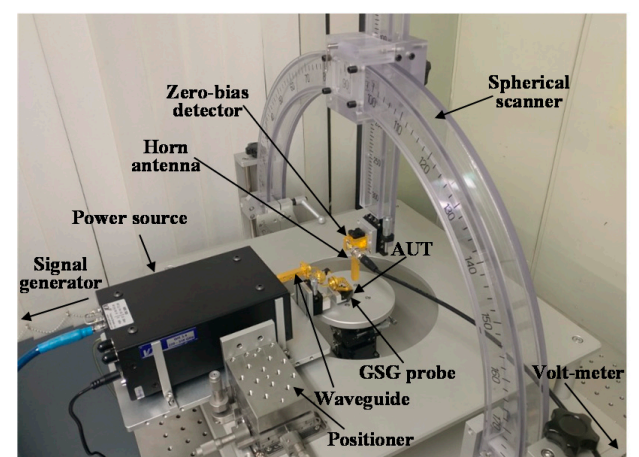

(b)

Figure 11. THz on-chip antenna measurement setup. (a) Diagram. (b) Photograph. 
Figure 12a shows the measured gain of the antenna with frequency. It was higher than about $15 \mathrm{dBi}$ from 280 to $320 \mathrm{GHz}$ with a peak gain of $5.48 \mathrm{dBi}$ at $295 \mathrm{GHz}$. Figure $12 \mathrm{~b}$ shows the measured radiation pattern at a peak gain frequency of $295 \mathrm{GHz}$. Both figures show close agreement with the simulation results.

The reported THz CMOS on-chip antennas are compared in Table 2. The proposed $V$-shaped patch antenna in this work exhibited the best bandwidth performance (meeting reflection coefficient lower than $-10 \mathrm{~dB}$ ). Furthermore, the gain was the best among on-chip antennas without using additional external components or processes such as dielectric resonators [20], lens [23], or wafer thinning [22]. Note that most publications in this table do not provide the measurement results of the on-chip antenna, because of the difficulties of the THz on-chip antenna measurement.

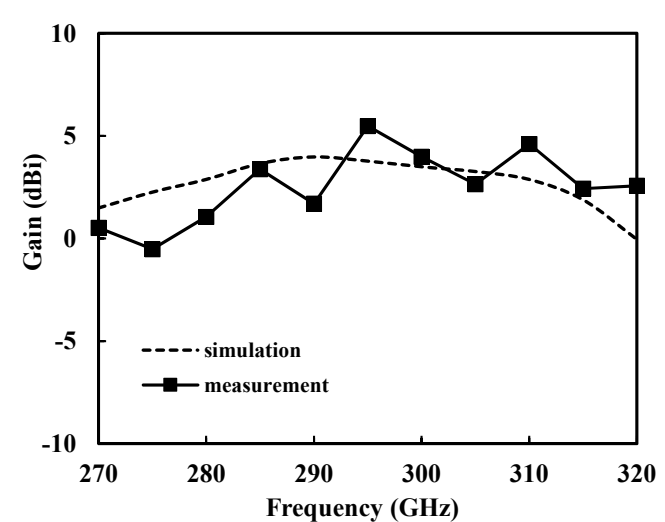

(a)

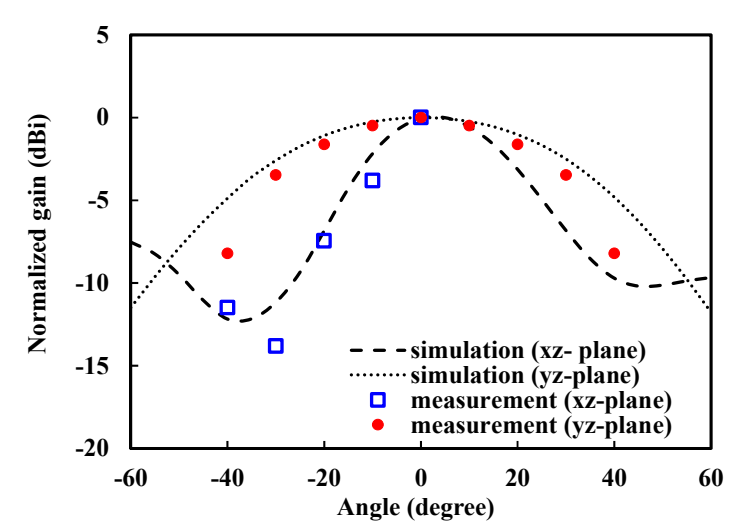

(b)

Figure 12. Measured performance of the fabricated antenna. (a) Gain as a function of frequency; (b) Radiation pattern at a peak gain frequency $(295 \mathrm{GHz})$. Simulation results include the probe tip.

Table 2. Comparison of the reported Si CMOS on-chip antennas operating around $300 \mathrm{GHz}$.

\begin{tabular}{|c|c|c|c|c|c|c|c|c|}
\hline & This Work & [1] & [36] & [37] & [38] & [39] & [20] & [23] \\
\hline Center frequency $(\mathrm{GHz})$ & 290 & 240 & 280 & 340 & 270 & 210 & 340 & 288 \\
\hline Peak efficiency (\%) & $26.3 *$ & $11.4 *$ & $21 *$ & $6.5 *$ & $21.4^{*}$ & $24 *$ & 80 & 65 \\
\hline Peak gain (dBi) & 5.48 & 1.55 * & $-1.6^{*}$ & $-5.5 *$ & $-0.5 *$ & $-2.5 *$ & 10 & n.a. \\
\hline Type & Patch & Slotted loop & Patch & Patch & SIW $^{2}$ & Dipole & $\mathrm{DRA}^{3}$ & HHLA $^{4}$ \\
\hline
\end{tabular}

* Simulation result; ${ }^{1}$ Bandwidth of input reflection coefficient $<-10 \mathrm{~dB} ;{ }^{2}$ Substrate-integrated-waveguide; ${ }^{3}$ DRA: dielectric resonator antenna; ${ }^{4}$ HHLA: hyper-hemispherical lens antenna.

\section{Conclusions}

In this paper, a front-side radiating CMOS patch antenna was studied to enhance bandwidth and efficiency. Several ideas were proposed to overcome the problems caused by a very thin dielectric substrate in the standard CMOS process. At first, the standard patch antenna was modified for wide impedance matching bandwidth by proposing the slotted $V$-shaped patch with an extra resonator stacked on top. Then, a defected ground structure was proposed to increase the radiation resistance for high efficiency and wide bandwidth. The simulation verified that the leakage wave in Si substrate through the slots in the ground plane can be added in phase with the front-side radiating wave from the patch, leading to an enhancement in directivity and gain. In addition, it was also proved by the simulation that the probe used in the on-wafer measurement can affect the radiation pattern of the on-chip antenna.

The fabricated $V$-shaped CMOS on-chip antenna was measured using the developed $\mathrm{THz}$ antenna measurement setup. It exhibits a very wide bandwidth (greater than $28.7 \%$ ) in the input 
reflection coefficient. The peak gain was $5.48 \mathrm{dBi}$ at $295 \mathrm{GHz}$. Therefore, the developed high-gain broadband antenna can be integrated in terahertz CMOS transceiver circuits for communications and imaging applications.

Author Contributions: Conceptualization, J.J.; Methodology, H.K., W.C., and J.J.; Validation, H.K., W.C., and J.J.; Formal Analysis, H.K. and W.C.; Investigation, H.K.; Data Curation, H.K.; Writing-Original Draft Preparation, J.J.; Writing-Review \& Editing, J.J.; Visualization, H.K.; Supervision, J.J.; Project Administration, J.J.; Funding Acquisition, J.J.

Funding: This work was supported by a grant to Terahertz Electronic Device Research Laboratory funded by Defense Acquisition Program Administration, and by Agency for Defense Development (UD180025RD).

Conflicts of Interest: The authors declare no conflict of interest.

\section{References}

1. Kang, S.; Thyagarajan, S.V.; Niknejad, A.M. A $240 \mathrm{GHz}$ fully integrated wideband QPSK transmitter in $65 \mathrm{~nm}$ CMOS. IEEE J. Solid-State Circuits 2015, 50, 2256-2267. [CrossRef]

2. Kallfass, I.; Antes, J.; Schneider, T.; Kurz, F.; Lopez-Diaz, D.; Diebold, S.; Massler, H.; Leuther, A.; Tessmann, A. All active MMIC-based wireless communication at $220 \mathrm{GHz}$. IEEE Trans. Terahertz Sci. Technol. 2011, 1, 477-487. [CrossRef]

3. Tesssmann, A.; Leuther, A.; Hurm, V.; Massler, H.; Wagner, S.; Kuri, M.; Zink, M.; Riessle, M.; Stulz, H.-P.; Schlechtweg, M.; et al. A broadband 220-320 GHz medium power amplifier module. In Proceedings of the IEEE Compound Semicond. Integrated Circuit Symposium, Monterey, CA, USA, 3-6 October 2010; pp. 1-4.

4. Lee, I.; Kim, J.; Jeon, S. A G-Band Frequency Doubler Using a Commercial 150 nm GaAs pHEMT Technology. J. Electromagn. Eng. Sci. 2017, 17, 147-152. [CrossRef]

5. Choe, W.; Kim, J.; Jeong, J. Full H-band waveguide-to-coupled microstrip transition using dipole antenna with directors. IEICE Electron. Express 2017, 14, 20170487. [CrossRef]

6. Kim, J.; Choe, W.; Jeong, J. Submillimeter-wave waveguide-to-microstrip transitions for wide circuits/wafers. IEEE Trans. Terahertz Sci. Technol. 2017, 7, 440-445. [CrossRef]

7. Sengupta, K.; Seo, D.; Yang, L.; Hajimiri, A. Silicon integrated $280 \mathrm{GHz}$ imaging chipset with $4 \times 4 \mathrm{SiGe}$ receiver array and CMOS source. IEEE Trans. Terahertz Sci. Technol. 2015, 5, 427-437.

8. Yan, Y.; Karandikar, Y.B.; Gunnarsson, S.E.; Urteaga, M.; Pierson, R.; Zirath, H. 340 GHz integrated receiver in $250 \mathrm{~nm}$ InP DHBT technology. IEEE Trans. Terahertz Sci. Technol. 2012, 2, 306-314. [CrossRef]

9. Kim, J.; Jeon, S.; Kim, M.; Urteaga, M.; Jeong, J. H-band power amplifier integrated circuits using 250-nm InP HBT technology. IEEE Trans. Terahertz Sci. Technol. 2015, 5, 215-222. [CrossRef]

10. Kim, J.; Seo, M.; Rieh, J. A CMOS 180-GHz Signal Source with an Integrated Frequency Doubler. J. Electromagn. Eng. Sci. 2016, 16, 229-231. [CrossRef]

11. Bhutani, A.; Gulan, H.; Goettel, B.; Heine, C.; Thelemann, T.; Pauli, M.; Zwick, T. 122 GHz aperture-coupled stacked patch microstrip antenna in LTCC technology. In Proceedings of the 10th European Conference on Antennas and Propagation (EuCAP), Davos, Switzerland, 10-15 April 2016; pp. 1-5.

12. Syed, W.H.; Florentino, G.; Cavallo, D.; Spirito, M.; Sarro, P.M.; Neto, A. Design, fabrication, and measurements of a $0.3 \mathrm{THz}$ on-chip double slot antenna enhanced by artificial dielectrics. IEEE Trans. Terahertz Sci. Technol. 2015, 5, 288-298. [CrossRef]

13. Hu, S.; Xiong, Y.-Z.; Zhang, B.; Wang, L.; Lim, T.-G.; Je, M.; Madihian, M. A SiGe BiCMOS transmitter/receiver chipset with on-chip SIW antenna for terahertz applications. IEEE J. Solid-State Circuits 2015, 50, 2256-2267. [CrossRef]

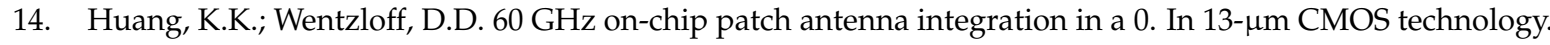
In Proceedings of the IEEE International Conference on Ultra-Wideband (ICUWB), Nanjing, China, 20-23 September 2010.

15. Nafe, M.; Syed, A.; Shamim, A. Gain enhancement of low profile on-chip dipole antenna via artificial magnetic conductor at $94 \mathrm{GHz}$. In Proceedings of the 9th European Conference on Antennas and Propagation (EuCAP), Lisbon, Portugal, 13-17 April 2015; pp. 1-3. 
16. Mosallaei, H.; Sarabandi, K. Antenna Miniaturization and Bandwidth Enhancement using a Reactive Impedance Substrate. IEEE Trans. Antennas Propag. 2004, 52, 2403-2414. [CrossRef]

17. Li, L.; Li, Y.; Yeo, T.; Mosig, J.; Martin, O. A Broadband and High-Gain Metamaterial Microstrip Antenna. Appl. Phys. Lett. 2010, 96, 164101. [CrossRef]

18. Yao, J.; Tchafa, F.; Jain, A.; Tjuatja, S.; Huang, H. Far-Field Interrogation of Microstrip Patch Antenna for Temperature Sensing without Electronics. IEEE Sens. J. 2016, 16, 7053-7060. [CrossRef]

19. Tajima, T.; Song, H.; Yaita, M. Compact THz LTCC receiver module for $300 \mathrm{GHz}$ wireless communications. IEEE Microw. Compon. Lett. 2016, 26, 291-293. [CrossRef]

20. Deng, X.; Li, Y.; Liu, C.; Wu, W.; Xiong, Y. $340 \mathrm{GHz}$ on-chip 3-D antenna with $10 \mathrm{dBi}$ gain and 80\% radiation efficiency. IEEE Trans. Terahertz Sci. Technol. 2015, 5, 619-627. [CrossRef]

21. Song, H.; Kim, J.; Ajito, K.; Yaita, M.; Kukutsu, N. Fully integrated ASK receiver MMIC for terahertz communications at 300 GHz. IEEE Trans. Terahertz Sci. Technol. 2013, 3, 445-452. [CrossRef]

22. Babakhani, A.; Rutledge, D.B.; Hajimiri, A. Mm-wave phased arrays in silicon with integrated antennas. In Proceedings of the IEEE Antennas and Propagation Society International Symposium, Honolulu, HI, USA, 9-15 June 2007; pp. 4369-4372.

23. Grzyb, J.; Zhao, Y.; Pfeiffer, U.R. A 288 GHz lens-integrated balanced triple-push source in a 65-nm CMOS technology. IEEE J. Solid-State Circuits 2013, 48, 1751-1761. [CrossRef]

24. Schuster, F.; Videlier, H.; Dupret, A.; Coquillat, D.; Sakowicz, M.; Rostaing, J.P.; Tchagaspanian, M.; Giffard, B.; Knap, W. A Broadband THz Imager in a Low-Cost CMOS Technology. In Proceedings of the IEEE International Solid-State Circuits Conference, San Francisco, CA, USA, 20-24 February 2011; pp. $42-43$.

25. Schuster, F.; Coquillat, D.; Videlier, H.; Sakowicz, M.; Teppe, F.; Dussopt, L.; Giffard, B.; Skotnicki, T.; Knap, W. Broadband Terahertz imaging with highly sensitive silicon CMOS detectors. Opt. Express 2011, 19, 7827-7832. [CrossRef] [PubMed]

26. Khan, M.S.; Tahir, F.A.; Cheema, H.M. Design of Bowtie-Slot On-chip Antenna Backed with E-Shaped FSS at $94 \mathrm{GHz}$. In Proceedings of the 10th European Conference on Antenna and Propagation, Davos, Switzerland, 10-15 April 2016; pp. 1-3.

27. Arz, U. Microwave Substrate Loss Tangent Extraction from Coplanar Waveguide Measurements up to $125 \mathrm{GHz}$. In Proceedings of the 83rd ARFTG Microwave Measurement Conference, Tampa, FL, USA, 6 June 2014; pp. 1-3.

28. Majid, H.A.; Rahim, M.K.A.; Hamid, M.R.; Murad, N.A.; Ismail, M.F. Frequency-reconfigurable microstrip patch-slot antenna. IEEE Antenna Wirel. Propag. Lett. 2013, 12, 218-220. [CrossRef]

29. Misra, I.S.; Murmu, S.K. Design of V-shaped microstrip patch antenna at $2.4 \mathrm{GHz}$. Microw. Opt. Technol. Lett. 2011, 53, 806-811.

30. Johannsen, U.; Smolders, A.B.; Mahmoudi, R. Substrate loss reduction in antenna-on-chip design. In Proceedings of the IEEE Antennas and Propagation Society International Symposium, Charleston, SC, USA, 1-5 June 2009; pp. $1-4$.

31. Simons, R.N. Novel On-Wafer Radiation Pattern Measurement Technique for MEMS Actuator Based Reconfigurable Patch Antennas; NASA STI/Recon Technical Report N; NASA Glenn Research Center: Cleveland, OH, USA, 2002.

32. Pan, S.; Gilreath, L.; Heydari, P.; Capolino, F. Investigation of a Wideband BiCMOS Fully On-Chip W-band Bowtie Slot Antenna. IEEE Antennas Wirel. Propag. Lett. 2013, 12, 706-709. [CrossRef]

33. Balanis, C.A. Antenna Theory: Analysis and Design, 4th ed.; Wiley: New York, NY, USA, 2016; pp. 49-51.

34. Stutzman, W.L. Antenna Theory and Design, 3rd ed.; Wiley: New York, NY, USA, 2012; pp. 571-575.

35. Kang, J.; Kim, J.; Park, J. Comparison of antenna parameters of R-/S- band standard gain horn antennas. J. Electromagn. Eng. Sci. 2015, 15, 224-231. [CrossRef]

36. Han, R.; Zhang, Y.; Coquillat, D.; Videlier, H.; Knap, W.; Brown, E.; Kenneth, K.O. A 280-GHz schottky diode detector in 130-nm digital CMOS. IEEE J. Solid-State Circuits 2011, 46, 2602-2612. [CrossRef]

37. Li, C.H.; Ko, C.L.; Kuo, M.C.; Chang, D.C. A 340-GHz heterodyne receiver front end in 40-nm CMOS for THz biomedical imaging applications. IEEE Trans. Terahertz Sci. Technol. 2016, 6, 625-636. [CrossRef] 
38. Shang, Y.; Yu, H.; Fu, H.; Lim, W.M. A 239-281 GHz CMOS receiver with on-chip circular-polarized substrate integrated waveguide antenna for sub-terahertz imaging. IEEE Trans. Terahertz Sci. Technol. 2014, 4, 686-695. [CrossRef]

39. Wang, Z.; Chiang, P.-Y.; Nazari, P.; Wang, C.-C.; Chen, Z.; Heydari, P. A CMOS 210-GHz fundamental transceiver with OOK modulation. IEEE J. Solid-State Circuits 2014, 49, 564-580. [CrossRef] 